\title{
Características produtivas e imunológicas de frangos de corte submetidos a dietas suplementadas com cromo, criados sob diferentes condições de ambiente
}

\author{
Alexandre $\mathrm{Oba}^{1}$, Patrícia Cristina Ferro Lopes ${ }^{2}$, Marcel Manente Boiago ${ }^{3}$, Aline Mary \\ Scatolini Silva ${ }^{3}$, Hélio José Montassier ${ }^{2}$, Pedro Alves de Souza ${ }^{3}$ \\ ${ }^{1}$ Departamento de Zootecnia - Universidade Estadual de Londrina. \\ 2 Departamento de Patologia - Universidade Estadual Paulista, Campus Jaboticabal. \\ ${ }^{3}$ Departamento de Tecnologia - Universidade Estadual Paulista, Campus Jaboticabal.
}

RESUMO - Objetivou-se avaliar o desempenho, a resposta imune e as características de carcaça de frangos de corte alimentados com dietas suplementadas com cromo complexado a levedura (Saccharomyces cerevisae), criados em diferentes condições de temperatura. O experimento foi conduzido em câmaras climáticas com sistema de aquecimento e refrigeração, utilizando-se as seguintes condições de temperatura, de acordo com as idades: 1 a 3 dias $\left(35,35\right.$ e $\left.35^{\circ} \mathrm{C} \pm 2\right), 4$ a 7 dias $\left(35,30,25{ }^{\circ} \mathrm{C} \pm 2\right), 8$ a 14 $\operatorname{dias}\left(34,27\right.$ e $\left.20^{\circ} \mathrm{C} \pm 2\right), 15$ a 21 dias $\left(33,26\right.$ e $\left.18^{\circ} \mathrm{C} \pm 2\right)$ e de 22 a 47 dias $\left(32,26\right.$ e $\left.18{ }^{\circ} \mathrm{C} \pm 2\right)$, respectivamente, para temperatura quente, termoneutra e fria. As dietas foram suplementadas com 0, 400, 800, $1.200 \mu \mathrm{g} \mathrm{Cr} / \mathrm{kg}$. A suplementação de $400 \mu \mathrm{g} \mathrm{Cr} / \mathrm{kg} \mathrm{melhora}$ a viabilidade e, em aves mantidas em temperatura quente, a conversão alimentar, enquanto a temperatura de criação mostrou ter grande influência sobre as características produtivas em todas as fases de criação. As aves criadas em temperatura quente apresentam melhor resposta imune, maior rendimento de carcaça e pernas e resultados inferiores de desempenho e rendimento de peito.

Palavras-chave: anticorpo, desempenho, estresse térmico, rendimento carcaça

\section{Productive and immunological traits of broiler chickens fed diets supplemented with chromium, reared under different environmental conditions}

\begin{abstract}
The objective of this experiment was to evaluate performance, immune response and traits concerning carcass and poultry cuts of broiler chickens fed diets supplemented with chromium-yeast (Saccharomyces cerevisae), reared under different environmental temperature conditions. Birds were reared in climate chambers with heating and cooling system, using the following environmental temperatures according to ages: from 1 to 3 days of age $\left(35,35\right.$ and $\left.35{ }^{\circ} \mathrm{C} \pm 2\right)$, from 4 to 7 days of age $\left(35,30\right.$ and $25^{\circ} \mathrm{C} \pm 2$ ), from 8 to 14 days old $\left(34,27\right.$ and $20^{\circ} \mathrm{C} \pm 2$ ), from 15 to 21 days of age (33, 26 and $\left.18{ }^{\circ} \mathrm{C} \pm 2\right)$ and from 22 to 47 days of age $\left(32,26\right.$ and $\left.18^{\circ} \mathrm{C} \pm 2\right)$, respectively, for high, thermoneutral and low temperatures. Diets were supplemented with $0 ; 400 ; 800$; and $1,200 \mu \mathrm{g} \mathrm{Cr} / \mathrm{kg}$. Supplementation with $400 \mu \mathrm{g} \mathrm{Cr} / \mathrm{kg}$ enhances the viability and, in birds reared in high temperature, feed conversion as well, while temperature showed to have great influence upon productive traits in every rearing phase. Chickens reared at high temperature presented better immune response, higher carcass dressing percentage and leg quarter yield, but inferior results for breast yield and performance.
\end{abstract}

Key Words: antibody, dressing percentage, performance, thermal stress

\section{Introdução}

Os frangos estão cada vez mais precoces e com maior ganho de peso. Por outro lado, tem se observado aumento de gordura na carcaça, principalmente na região abdominal. A composição da carcaça e o rendimento de carne dependem da nutrição, do manejo, da genética e das condições de ambiente. Sabe-se que altas temperaturas proporcionam menores rendimentos de peito e maior deposição de gordura na carcaça (Ain Baziz et al., 1996). Segundo Furlan \& Macari
(2002), a zona de conforto térmico das aves reduz de $35^{\circ} \mathrm{C}$ no nascimento para aproximadamente $24^{\circ} \mathrm{C}$ às 4 semanas e para $21 \mathrm{a} 22^{\circ} \mathrm{C}$ às 6 semanas de idade.

A exposição dos animais a condições ambientais adversas promove respostas adaptativas como aclimatação, ocorrendo uma cascata de reações que culminam com a secreção de glicocorticoides, que atuam de forma antagônica ao desenvolvimento e à resposta imune dos animais.

A nutrição é outro ponto crítico na manutenção da homeostase imunológica, visto que a deficiência de 
micronutrientes produz grande espectro de danos, que incluem desde desordens clínicas decorrentes de deficiências severas a problemas funcionais sutis em deficiências subclínicas, que podem influenciar significativamente a saúde e sobrevivência animal (Bhaskaram, 2001).

O cromo reduz o estresse térmico pela redução dos glicocorticoides, melhorando o desempenho, a qualidade da carne e a resistência a patógenos. A absorção pelo organismo animal depende de sua forma de disponibilidade. $\mathrm{Na}$ forma inorgânica (cloreto ou acetato), possui absorção intestinal de 0,4 a $3 \%$ e sua excessiva ingestão não resulta em absorção eficiente (Hossain, 1998), enquanto o cromo quelatado apresenta absorção intestinal de 15 a $30 \%$, visto que, no trato digestório, apresenta-se estável, impedindo sua complexação com outro mineral e sua absorção ocorre por mecanismos relacionados ao elemento em que está complexado.

Objetivou-se avaliar o desempenho, as características de carcaça e a resposta imune de frangos de corte alimentados com dietas suplementadas com diferentes níveis cromo complexado a levedura (Saccharomyces cerevisae) e mantidos sob diferentes condições de temperatura.

\section{Material e Métodos}

Foram utilizados 960 pintos de corte machos, da linhagem Cobb, com 1 dia de idade, alojados em três câmaras climáticas composta de 16 boxes $(2,5 \times 1,00 \mathrm{~m})$. As câmaras eram revestidas com poliuretano e apresentavam sistema de aquecimento e refrigeração. As aves receberam água e alimento à vontade durante todo o período experimental e foram submetidas às diferentes condições de temperatura (Tabela 1).

As rações utilizadas foram isonutritivas, formuladas para atender às recomendações nutricionais do NRC (1994), e apresentaram quatro níveis de cromo complexado à levedura: 0, 400, 800 e $1.200 \mu \mathrm{g} / \mathrm{kg}$ dieta (Tabela 2). A concentração de cromo na levedura utilizada foi de 1.644,75 $\mathrm{mg} / \mathrm{kg}$ e a quantidade de levedura, independentemente do nível de cromo, foi sempre a mesma, uma vez que, nos menores níveis, foram acrescentadas leveduras sem cromo.

No final de cada fase de criação (inicial: 1 a 21 dias; crescimento: 22 a 40 dias; acabamento: 41 a 47 dias), foram avaliados os seguintes índices zootécnicos: ganho de peso, consumo de ração, conversão alimentar e viabilidade de criação, que foi determinada pelo número de aves no

Tabela 1 - Temperaturas utilizadas na criação dos frangos de corte

\begin{tabular}{lccc}
\hline Idade das aves & \multicolumn{3}{c}{ Temperatura ambiente } \\
\cline { 2 - 4 } & Quente & Termoneutra & Fria \\
\hline 1 a 3 dias & $35 \pm 2{ }^{\circ} \mathrm{C}$ & $35 \pm 2{ }^{\circ} \mathrm{C}$ & $35 \pm 2{ }^{\circ} \mathrm{C}$ \\
4 a 7 dias & $35 \pm 2{ }^{\circ} \mathrm{C}$ & $30 \pm 2{ }^{\circ} \mathrm{C}$ & $25 \pm 2{ }^{\circ} \mathrm{C}$ \\
8 a 14 dias & $34 \pm 2{ }^{\circ} \mathrm{C}$ & $27 \pm 2{ }^{\circ} \mathrm{C}$ & $20 \pm 2{ }^{\circ} \mathrm{C}$ \\
15 a 21 dias & $33 \pm 2{ }^{\circ} \mathrm{C}$ & $26 \pm 2{ }^{\circ} \mathrm{C}$ & $18 \pm 2{ }^{\circ} \mathrm{C}$ \\
22 a 47 dias & $32 \pm 2{ }^{\circ} \mathrm{C}$ & $26 \pm 2{ }^{\circ} \mathrm{C}$ & $18 \pm 2{ }^{\circ} \mathrm{C}$ \\
\hline
\end{tabular}

Tabela 2 - Composição porcentual e calculada das rações experimentais

\begin{tabular}{|c|c|c|c|}
\hline Ingrediente $(\%)$ & $\begin{array}{l}\text { Fase inicial, } \\
1 \text { a } 21 \text { dias }\end{array}$ & $\begin{array}{l}\text { Fase de crescimento, } \\
22 \text { a } 40 \text { dias }\end{array}$ & $\begin{array}{l}\text { Fase de terminação, } \\
41 \text { a } 47 \text { dias }\end{array}$ \\
\hline Milho & 53,55 & 60,17 & 65,03 \\
\hline Farelo de soja & 39,90 & 32,20 & 27,50 \\
\hline Fosfato bicálcico & 2,00 & 2,00 & 1,60 \\
\hline Óleo de soja & 2,43 & 3,80 & 4,00 \\
\hline Suplemento vitamínico-minera ${ }^{1}$ & 0,50 & 0,50 & 0,50 \\
\hline Cromo complexado à levedura + levedura $^{2}$ & 0,07 & 0,07 & 0,07 \\
\hline \multirow[t]{2}{*}{ Total } & 100,00 & 100,00 & 100,00 \\
\hline & \multicolumn{3}{|c|}{ Composição química calculada } \\
\hline Proteína bruta $(\%)$ & 23,02 & 20,03 & 18,29 \\
\hline Energia metabolizável (kcal/kg) & 2.965 & 3.134 & 3.211 \\
\hline Fósforo disponível (\%) & 0,49 & 0,48 & 0,40 \\
\hline
\end{tabular}

${ }^{1}$ Composição do produto. Fase inicial: iodo - $273 \mathrm{mg} / \mathrm{kg}$; selênio - 59,28 mg/kg; manganês - $15.500 \mathrm{mg} / \mathrm{kg}$; zinco - $18.250 \mathrm{mg} / \mathrm{kg}$; vit. A - $1.900 .000 \mathrm{UI} / \mathrm{kg}$; vit. D $600.000 \mathrm{UI} / \mathrm{kg}$; vit. E - $2.500 \mathrm{mg} / \mathrm{kg}$; vit. K - $98 \mathrm{mg} / \mathrm{kg}$; vit. B1 - $356 \mathrm{mg} / \mathrm{kg}$; vit. B2 - $1.600 \mathrm{mg} / \mathrm{kg}$; vit. B6 - $693 \mathrm{mg} / \mathrm{kg}$; vit. B12 - $2.200 \mathrm{mg} / \mathrm{kg}$; ácido pantotênico - $1.710 \mathrm{mg} / \mathrm{kg}$; niacina - $15.840 \mathrm{mg} / \mathrm{kg}$; biotina - $32 \mathrm{mg} / \mathrm{kg}$; ácido fólico - $148 \mathrm{mg} / \mathrm{kg}$; colina - $144.000 \mathrm{mg} / \mathrm{kg}$; cobre - $25.000 \mathrm{mg} / \mathrm{kg}$; enxofre - 2,33\%. Crescimento: iodo - 260 mg/kg; selênio - 54,72 mg/kg; manganês - $18.600 \mathrm{mg} / \mathrm{kg}$; zinco - $18.250 \mathrm{mg} / \mathrm{kg}$; vit. A - $1.400 .000 \mathrm{UI} / \mathrm{kg}$; vit. D - $600.000 \mathrm{UI} / \mathrm{kg}$; vit. E - 2.000 mg/kg; vit. K - $98 \mathrm{mg} / \mathrm{kg}$; vit. B1 - $356 \mathrm{mg} / \mathrm{kg}$; vit. B2 - $1.600 \mathrm{mg} / \mathrm{kg}$; vit. B6 - $693 \mathrm{mg} / \mathrm{kg}$; vit. B12 - $3.200 \mathrm{mg} / \mathrm{kg}$; ácido pantotênico - $1.900 \mathrm{mg} / \mathrm{kg}$; niacina - $5.940 \mathrm{mg} / \mathrm{kg}$; biotina - $32 \mathrm{mg} / \mathrm{kg}$; ácido fólico - $40 \mathrm{mg} / \mathrm{kg}$; colina - $144.000 \mathrm{mg} / \mathrm{kg}$; cobre - $25.000 \mathrm{mg} / \mathrm{kg}$; sódio - 1,5\%; enxofre - 3,90\%; ferro - 5.400\%. Fase de terminação: iodo - 195 mg/kg; selênio $118,56 \mathrm{mg} / \mathrm{kg}$; manganês - $30.720 \mathrm{mg} / \mathrm{kg}$; zinco - $16.060 \mathrm{mg} / \mathrm{kg}$; vit. A - $1.400 .000 \mathrm{UI} / \mathrm{kg}$; vit. D - $100.000 \mathrm{UI} / \mathrm{kg}$; vit. E - $400 \mathrm{mg} / \mathrm{kg}$; vit. K - $196 \mathrm{mg} / \mathrm{kg}$; vit. B2 $672 \mathrm{mg} / \mathrm{kg}$; vit. B12 - $2.000 \mathrm{mg} / \mathrm{kg}$; ácido pantotênico - $3.800 \mathrm{mg} / \mathrm{kg}$; colina - $144.000 \mathrm{mg} / \mathrm{kg}$; cobre - $3.200 \mathrm{mg} / \mathrm{kg}$; e enxofre - $2 \%$.

$21.644,75 \mathrm{mg} \mathrm{Cr} / \mathrm{kg}$ levedura. As rações eram completadas com levedura sem cromo para eliminar o efeito da levedura. 
final do experimento, dividido pelo número de aves inicial, vezes 100 .

As aves foram vacinadas aos 8 dias, contra a doença de Newcastle (VDN - estirpe La Sota) e a doença de gumboro (VDG - cepa intermediária Lukert), e aos 18 dias, novamente contra gumboro (VDG - cepa forte Austrália V-877). Todas as vacinas foram via ocular, via diluente recomendado pelo fabricante na proporção de $30 \mathrm{~mL} / 1.000$ doses de vacina, equivalentes a $30 \mu \mathrm{L} /$ ave, de acordo com método descrito por Paulilo (1987). As amostras de sangue foram colhidas por punção na veia braquial da asa, sempre dos mesmos dois frangos por parcela, aos 7, 17, 27 e 37 dias. Após a obtenção do soro, estes foram congelados a $-20{ }^{\circ} \mathrm{C}$ até a realização das análises. Para realização das análises de títulos de anticorpos para VDN, foi utilizado o teste de inibição por hemaglutinação (HI), seguindo metodologia proposta por Cunnigham (1971), sendo que os títulos foram transformados em Log 2.

O delineamento experimental adotado foi o inteiramente casualizado, em esquema fatorial $3 \times 4$, composto de três temperaturas ambientes e quatro níveis de cromo, com 4 repetições de 20 aves por parcela.

No final do experimento, três aves representando o peso médio de cada parcela experimental, após 12 horas de jejum, foram abatidas para determinação de rendimento de carcaça e dos cortes, os quais foram obtidos a partir dos rendimentos quentes de carcaça e cortes, conforme descrito por Mendes (2001). A gordura abdominal incluiu toda a gordura depositada na moela e na cavidade abdominal.

As análises dos dados de desempenho, das características de carcaça e da resposta imune das aves foram realizadas utilizando-se o programa computacional SAEG (Sistema para Análises Estatísticas e Genéticas, versão 8.0). Após as análises de variância, quando a interação foi significativa, o efeito de cada nível de um fator foi estudado dentro do outro. Na ausência de interação, os principais efeitos foram avaliados pelo teste Tukey $(\mathrm{P}<0,05)$.

\section{Resultados e Discussão}

Os resultados de desempenho produtivo (Tabela 3) mostram que a temperatura do ambiente tem forte influência sobre as características produtivas, sendo que os menores índices $(\mathrm{P}<0,001)$ de ganho de peso $(2,18 \mathrm{~kg})$ e viabilidade $(85,94 \%)$ foram apresentados pelas aves mantidas em ambiente de temperatura quente. O consumo de ração das aves mantidas sob temperatura fria e quente foram maiores e menores (5,32 e 4,07 kg, respectivamente; $\mathrm{P}<0,001)$. Esses dados atestam melhor $(\mathrm{P}<0,001)$ conversão alimentar para as aves mantidas em temperatura termoneutra e pior $(\mathrm{P}<0,001)$ para as aves mantidas em temperatura quente $(1,72$ vs 1,87$)$. Estes resultados estão de acordo com relatos de Geraert et al. (1996) e Oliveira Neto et al. (2000), que, ao submeterem frangos de corte ao estresse por calor, observaram redução da ingestão de alimento, menor ganho de peso e piora na conversão alimentar. A principal consequência da exposição do animal ao calor é a redução na ingestão de alimento, visando reduzir a produção de calor endógeno (Furlan \& Macari, 2002). Segundo Ain Baziz et al. (1996), nas aves estressadas por calor, a redução do ganho de peso é maior que a ingestão de alimento, pois parte da ingestão de energia metabolizável é usada para dissipação de calor, prejudicando a conversão alimentar. Outro mecanismo que pode ser observado durante o estresse por calor é o desvio de sangue do trato digestório para os tecidos periféricos (Nolan et al., 1978), reduzindo dessa

Tabela 3 - Características produtivas de frangos de corte alimentados com dietas suplementadas com cromo e criados até os 47 dias sob diferentes temperaturas

\begin{tabular}{|c|c|c|c|c|}
\hline & Ganho peso $(\mathrm{kg})$ & Consumo de ração $(\mathrm{kg})$ & Conversão alimentar (kg/kg) & Viabilidade (\%) \\
\hline \multicolumn{5}{|l|}{ Temperatura ambiente (T) } \\
\hline Quente & $2,18 b^{1}$ & $4,07 \mathrm{c}$ & $1,87 \mathrm{a}$ & $85,94 b$ \\
\hline Termoneutra & $2,92 \mathrm{a}$ & $5,03 b$ & $1,72 \mathrm{c}$ & $97,81 \mathrm{a}$ \\
\hline Fria & $2,99 \mathrm{a}$ & $5,32 \mathrm{a}$ & $1,78 b$ & $93,75 \mathrm{a}$ \\
\hline Efeito & $\mathrm{P}<0,001$ & $\mathrm{P}<0,001$ & $\mathrm{P}<0,001$ & $\mathrm{P}<0,001$ \\
\hline DMS & 0,08 & 0,16 & 0,03 & 6,13 \\
\hline \multicolumn{5}{|l|}{ Nível de cromo (Cr) } \\
\hline $0 \mu \mathrm{g} / \mathrm{kg}$ & $2,68 \mathrm{a}$ & $4,78 \mathrm{a}$ & $1,79 \mathrm{ab}$ & $87,50 \mathrm{~b}$ \\
\hline $400 \mu \mathrm{g} / \mathrm{kg}$ & $2,73 \mathrm{a}$ & $4,81 \mathrm{a}$ & $1,76 b$ & $95,42 \mathrm{a}$ \\
\hline $800 \mu \mathrm{g} / \mathrm{kg}$ & $2,69 \mathrm{a}$ & $4,82 \mathrm{a}$ & $1,80 \mathrm{ab}$ & $94,58 \mathrm{ab}$ \\
\hline $1.200 \mu \mathrm{g} / \mathrm{kg}$ & $2,67 \mathrm{a}$ & $4,81 \mathrm{a}$ & $1,81 \mathrm{a}$ & $92,50 \mathrm{ab}$ \\
\hline Efeito & $\mathrm{P} \leq 0,410$ & $\mathrm{P} \leq 0,982$ & $\mathrm{P} \leq 0,024$ & $\mathrm{P} \leq 0,050$ \\
\hline DMS & 0,11 & 0,21 & 0,04 & 7,80 \\
\hline Efeito interação $\mathrm{T} \times \mathrm{Cr}$ & $\mathrm{P} \leq 0,707$ & $\mathrm{P} \leq 0,723$ & $\mathrm{P} \leq 0,015$ & $\mathrm{P} \leq 0,219$ \\
\hline Coeficiente de variação (\%) & 3,69 & 3,91 & 2,16 & 7,59 \\
\hline
\end{tabular}

${ }^{1} \mathrm{Na}$ mesma coluna, médias seguidas de letras diferentes, indicam diferenças estatísticas pelo teste de Tukey $(\mathrm{P}<0,05)$; DMS $=$ diferença mínima significativa. 
maneira a capacidade digestiva (Wallis \& Balnave, 1984). Puvadolpirod \& Thaxton (2000) induziram o estresse em aves por meio de implante de bomba de ACTH (hormônio adrenocorticotrófico), que liberava este hormônio a $8 \mathrm{UI} / \mathrm{kg}$ peso corporal/dia durante sete dias. O ACTH tem a função de estimular a produção de corticosterona (Mashaly et al., 1998), que, segundo Litwack \& Singer (1972), altera os níveis de várias enzimas digestivas. De acordo com Puvadolpirod \& Thaxton (2000), o fornecimento de ACTH aumenta da ingestão de água, que causa diluição, promovendo mudanças no $\mathrm{pH}$ e na osmolaridade da digesta, além de aumentar a taxa de passagem. Em função disto, foi observada redução na digestão da matéria seca, proteína, energia bruta e carboidratos, comprovando que o estresse reduz a digestibilidade dos nutrientes e, consequentemente, o desempenho do animal.

Os níveis de cromo não influenciaram o ganho de peso e consumo de ração, porém a suplementação de $400 \mu \mathrm{g} \mathrm{Cr} / \mathrm{kg}$ proporcionou melhor conversão alimentar em relação à suplementação de $1.200 \mu \mathrm{g} \mathrm{Cr} / \mathrm{kg}(\mathrm{P} \leq 0,024)$. A menor suplementação de cromo promoveu maior viabilidade em relação à ausência de suplementação $(95,42$ vs 87,50 ; $\mathrm{P} \leq 0,050)$. Os resultados de ganho de peso e consumo de ração são semelhantes aos obtidos por Debski et al. (2004), Suksombat \& Kanchanatawee (2005), Vaz et al. (2009), Anandhi et al. (2006) e Souza et al. (2010), enquanto o de conversão alimentar foi semelhante aos obtidos por Sahin et al. (2002) e Króliczewska et al. (2005).

Segundo Lien et al. (1999), a falta de resposta positiva no desempenho pode ser atribuída à baixa produção de insulina pelas células $\beta$ do pâncreas das aves, visto que o cromo tem como principal característica a potencialização da insulina, hormônio importante no metabolismo animal. Esta afirmação foi comprovada nesta pesquisa, com ou uso de kit de radioimunoensaio, que não foi sensível o suficiente para detecção da insulina.

Os resultados encontrados na literatura são muito contraditórios, por isso, mais estudos são necessários para esclarecer o exato mecanismo de ação do cromo sobre o desempenho das aves. Deve-se sempre lembrar que existem diferentes tipos de cromo que estão sendo utilizados nas pesquisas.

Houve interação entre temperatura de criação e níveis de cromo na dieta para a conversão alimentar, uma vez que a suplementação de cromo na dieta influenciou apenas nas aves mantidas em ambiente quente e o menor nível de cromo ( $400 \mu \mathrm{g} \mathrm{Cr} / \mathrm{kg}$ ) proporcionou a melhor conversão alimentar $(1,79 ; \mathrm{P}<0,001)$. Já a temperatura de criação comprovou que o ambiente quente proporcionou as piores $(\mathrm{P}<0,001)$ conversões alimentares em qualquer nível de cromo fornecido, mostrando que o fator temperatura de criação é fundamental para obtenção de uma boa conversão alimentar (Tabela 4).

Os resultados de rendimento de carcaça, cortes e gordura abdominal (Tabela 5) comprovam que a suplementação de cromo não influenciou os rendimentos de carcaça, dos cortes e da gordura abdominal. Resultados semelhantes para rendimento de carcaça foram obtidos por Sands \& Smith (1999), trabalhando com 200 e $400 \mu \mathrm{g} \mathrm{Cr} / \mathrm{kg}$ na forma de picolinato de cromo; Debski et al. (2004), suplementando $1 \mathrm{~g} \mathrm{Cr} / \mathrm{kg}$ na forma de cromo levedura; Anandhi et al. (2006), suplementando 250 a $750 \mu \mathrm{g} \mathrm{Cr} / \mathrm{kg}$ na forma orgânica; e Souza et al. (2010), suplementando 150 a $600 \mu \mathrm{g} \mathrm{Cr} / \mathrm{kg}$ na forma de tripicolinato de cromo. Segundo Walker (1993), o cromo poderia aumentar o rendimento de carcaça por melhorar a absorção de aminoácidos e síntese proteica, enquanto Page (1991), citado por Chen et al. (2001), sugeriram que a dieta com cromo aumenta a liberação do hormônio de crescimento, que promove aumento do desenvolvimento muscular.

A temperatura de criação induziu alterações significativas nos rendimentos, pois aves mantidas em temperatura quente, apresentaram maior $(\mathrm{P}<0,001)$ rendimento de carcaça $(73,26 \%)$ em comparação às mantidas em temperatura fria $(69,90 \%)$, que apresentaram o menor $(\mathrm{P}<0,001)$ rendimento. Resultados semelhantes foram obtidos por Sands \& Smith (1999), que, ao submeterem frangos de corte ao estresse por calor, observaram aumento no rendimento de carcaça e pernas e redução no rendimento de peito. Oliveira Neto et al. (2000) mantiveram frangos em temperaturas quentes e observaram maior rendimento de carcaça, menor rendimento de pernas e peito e aumento de gordura abdominal. Esses resultados podem estar relacionados a menor desenvolvimento das vísceras das aves mantidas em ambiente quente, visto que estas ingerem menor quantidade de alimento, resultando em menor peso em relação à carcaça, proporcionando assim maior rendimento.

Tabela 4 - Desdobramento da interação entre as temperaturas de criação e níveis de cromo para conversão alimentar de frangos de corte criados até os 47 dias de idade

\begin{tabular}{lcccc}
\hline Nível de cromo & \multicolumn{3}{c}{ Temperatura ambiente } & Efeito \\
\cline { 2 - 4 } & Quente & Termoneutra & Fria & \\
\hline $0 \mu \mathrm{g} \mathrm{Cr} / \mathrm{kg}$ & $1,90 \mathrm{aA}{ }^{1}$ & $1,72 \mathrm{aB}$ & $1,77 \mathrm{aB}$ & $\mathrm{P}<0,001$ \\
$400 \mu \mathrm{g} \mathrm{Cr} / \mathrm{kg}$ & $1,79 \mathrm{bA}$ & $1,72 \mathrm{aB}$ & $1,77 \mathrm{aAB}$ & $\mathrm{P} \leq 0,042$ \\
$800 \mu \mathrm{g} \mathrm{Cr} / \mathrm{kg}$ & $1,87 \mathrm{aA}$ & $1,74 \mathrm{aB}$ & $1,77 \mathrm{aB}$ & $\mathrm{P}<0,001$ \\
$1200 \mu \mathrm{g} \mathrm{Cr} / \mathrm{kg}$ & $1,91 \mathrm{aA}$ & $1,71 \mathrm{aC}$ & $1,81 \mathrm{aB}$ & $\mathrm{P}<0,001$ \\
Efeito & $\mathrm{P}<0,001$ & $\mathrm{P}<0,643$ & $\mathrm{P}<0,308$ & \\
\hline
\end{tabular}

Diferença mínima significativa para teste Tukey para temperaturas ambientes $=$ 0,07 e níveis de cromo $=0,06$.

${ }^{1} \mathrm{Na}$ mesma coluna, médias seguidas de letras minúsculas diferentes, e na mesma linha, médias seguidas de letras maiúsculas diferentes, indicam diferenças estatísticas $(\mathrm{P}<0,05)$ pelo teste Tukey. 
Tabela 5 - Rendimento de carcaça, dos cortes e da gordura abdominal de frangos de corte alimentados com dietas suplementadas com diferentes níveis de cromo e mantidos em ambiente de diferentes temperaturas abatidos aos 47 dias

\begin{tabular}{|c|c|c|c|c|c|c|}
\hline \multirow[t]{2}{*}{ Tratamentos } & \multicolumn{6}{|c|}{ Rendimento $(\%)$} \\
\hline & Carcaça & Peito & Pernas & Asas & Dorso & Gordura abdominal \\
\hline \multicolumn{7}{|l|}{ Temperatura ambientes $(\mathrm{T})$} \\
\hline Termoneutra & $71,20 \mathrm{~b}$ & $34,05 \mathrm{a}$ & $33,32 b$ & $11,46 b$ & $18,96 \mathrm{a}$ & $2,23 \mathrm{a}$ \\
\hline Fria & $69,90 \mathrm{c}$ & $34,89 \mathrm{a}$ & $32,61 \mathrm{~b}$ & $11,80 \mathrm{a}$ & $18,92 \mathrm{a}$ & $1,79 \mathrm{a}$ \\
\hline Efeito & $\mathrm{P}<0,001$ & $\mathrm{P}<0,001$ & $\mathrm{P}<0,001$ & $\mathrm{P} \leq 0,003$ & $P \leq 0,036$ & $\mathrm{P} \leq 0,051$ \\
\hline $0 \mu \mathrm{g} / \mathrm{kg}$ & $71,22 \mathrm{a}$ & $33,90 \mathrm{a}$ & $33,59 \mathrm{a}$ & $11,68 \mathrm{a}$ & $18,93 \mathrm{a}$ & $1,91 \mathrm{a}$ \\
\hline $400 \mu \mathrm{g} / \mathrm{kg}$ & $71,14 \mathrm{a}$ & $33,46 a$ & $33,44 \mathrm{a}$ & $11,80 \mathrm{a}$ & $19,28 \mathrm{a}$ & $1,96 \mathrm{a}$ \\
\hline $800 \mu \mathrm{g} / \mathrm{kg}$ & $71,43 \mathrm{a}$ & $33,74 a$ & $33,69 a$ & $11,72 \mathrm{a}$ & $18,91 \mathrm{a}$ & $1,95 \mathrm{a}$ \\
\hline $1.200 \mu \mathrm{g} / \mathrm{kg}$ & $72,03 \mathrm{a}$ & $33,47 \mathrm{a}$ & $33,38 \mathrm{a}$ & $11,66 \mathrm{a}$ & $19,45 \mathrm{a}$ & $2,06 \mathrm{a}$ \\
\hline Efeito & $\mathrm{P} \leq 0,277$ & $\mathrm{P} \leq 0,794$ & $\mathrm{P} \leq 0,894$ & $\mathrm{P} \leq 0,738$ & $\mathrm{P} \leq 0,222$ & $\mathrm{P} \leq 0,905$ \\
\hline DMS & 1,34 & 1,41 & 1,20 & 0,38 & 0,82 & 0,57 \\
\hline
\end{tabular}

As aves mantidas sob estresse por calor apresentaram o menor rendimento de peito $(31,98 \% ; \mathrm{P}<0,001)$ e o maior rendimento de pernas $(34,65 \% ; \mathrm{P}<0,001)$ em comparação às demais temperaturas de criação. Estes resultados estão de acordo com os descritos por Temim et al. (2000), que, criando frangos de corte sob condições de estresse por calor, observaram redução na porcentagem do músculo do peito e aumento dos músculos das pernas. Ainda de acordo com esses autores, estes resultados podem ser pelo fato de que a musculatura do peito apresenta metabolismo glicolítico (fibras brancas) e a das pernas, metabolismo oxidativo (fibras vermelhas). Com isso, devido à ofegação das aves durante o estresse pelo calor, ocorre maior atividade da musculatura peitoral, consumindo parte das reservas de glicogênio e prejudicando o desenvolvimento muscular. Já o maior rendimento das pernas decorre do fato de que esta é constituída por grande quantidade de fibras vermelhas e apresenta considerável reserva de gordura, que é utilizada como fonte energética. Além disso, na escala de desenvolvimento dos tecidos, o ósseo se desenvolve principalmente na fase inicial, período em que a ave não é tão sensível ao calor, apresentando assim bom desenvolvimento. Já a musculatura do peito tem grande desenvolvimento no final do período de crescimento, quando as aves são mais sensíveis ao estresse por calor e por isso não desenvolvem este músculo. As aves mantidas em temperatura termoneutra apresentaram menores rendimentos de asas $(11,46 \% ; \mathrm{P} \leq 0,003)$ em relação às mantidas em temperatura quente $(11,89 \%)$ e fria $(11,80 \%)$. Como apresentam pouca massa muscular, as asas não sofreram alterações, mas em relação aos rendimentos de peito e pernas, apresentaram alterações, pois ficaram proporcional- mente reduzida. Os rendimentos de dorso e gordura abdominal não foram afetados pelas temperaturas de criação. Diferentemente dos resultados encontrados por Sands \& Smith (1999) e Oliveira Neto (2000), que obtiveram menores porcentagens de gordura abdominal nas aves submetidas ao estresse térmico quente. Esta condição pode ter sido devido à liberação de glicocorticoides, que atuam nas células adiposas, aumentando a liberação de ácidos graxos para a produção de acetil coenzima A, que sofre fosforilação oxidativa para manter e também repor os níveis celulares de ATP.

Os resultados de resposta imune humoral para VDN (Tabela 6) indicam que a suplementação de cromo não promoveu qualquer efeito nos parâmetros avaliados. Esses resultados são semelhantes aos encontrados e descritos por Wang et al. (1999), que, suplementando a dieta de frangos de corte com 0, 200, 400 e $600 \mathrm{mg} \mathrm{Cr} / \mathrm{kg}$, não detectaram qualquer efeito sobre o título de anticorpo para VDN até 3 semanas de idade. Pelo contrário, Guo et al. (1999), Lee et al. (2003) e Kheiri \& Toghyani (2009) suplementando a dieta de frangos de corte com cromo, observaram aumento significativo do título de anticorpos para VDN. Segundo estes autores, o cromo pode melhorar a efetividade da vacinação pelo aumento da função imune, pela redução de corticosterona ou mediadores liberados por células do sistema imune. Segundo Gross (1988), ao fornecer $25 \mathrm{mg}$ corticosterona na alimentação de frangos, houve menor título de anticorpos quando foram inoculados eritrócitos de ovinos. Já Wang et al. (1996) descreveram que o cromo melhora a resposta imune, por sua ação na liberação de citocinas, responsáveis por promover a ativação dos componentes do sistema imune. 
Tabela 6 - Valores médios dos títulos de anticorpos inibidores de hemaglutinação (HI) obtidos dos soros de frangos de corte suplementados com 4 níveis de cromo e mantidos em 3 temperaturas distintas

\begin{tabular}{|c|c|c|c|c|c|}
\hline \multirow[t]{2}{*}{ Tratamentos } & \multicolumn{5}{|c|}{ Idade das aves } \\
\hline & 7 dias & 17 dias & 27 dias & 37 dias & 47 dias \\
\hline \multicolumn{6}{|l|}{ Temp. ambientes $(\mathrm{T})$} \\
\hline Termoneutra & $7,69 \mathrm{a}$ & $5,62 \mathrm{c}$ & $7,16 \mathrm{a}$ & $6,19 a$ & $5,63 \mathrm{a}$ \\
\hline Fria & $7,03 \mathrm{~b}$ & $6,44 \mathrm{~b}$ & $6,81 \mathrm{a}$ & $6,16 a$ & $4,47 b$ \\
\hline Efeito & $\mathrm{P} \leq 0,033$ & $\mathrm{P}<0,001$ & $\mathrm{P} \leq 0,382$ & $P \leq 0,474$ & $\mathrm{P}<0,001$ \\
\hline DMS & 0,59 & 0,49 & 0,98 & 1,11 & 0,89 \\
\hline \multicolumn{6}{|l|}{ Níveis de cromo $(\mathrm{Cr})$} \\
\hline $0 \mu \mathrm{g} / \mathrm{kg}$ & $7,25 \mathrm{a}$ & $6,21 \mathrm{a}$ & $6,54 \mathrm{a}$ & $6,00 \mathrm{a}$ & $5,17 \mathrm{a}$ \\
\hline $400 \mu \mathrm{g} / \mathrm{kg}$ & $7,46 \mathrm{a}$ & $6,67 \mathrm{a}$ & $6,87 \mathrm{a}$ & $6,12 \mathrm{a}$ & $5,25 \mathrm{a}$ \\
\hline $800 \mu \mathrm{g} / \mathrm{kg}$ & $7,37 \mathrm{a}$ & $6,37 \mathrm{a}$ & $7,04 \mathrm{a}$ & $5,96 \mathrm{a}$ & $5,75 \mathrm{a}$ \\
\hline $1.200 \mu \mathrm{g} / \mathrm{kg}$ & $7,42 \mathrm{a}$ & $6,75 \mathrm{a}$ & $6,96 a$ & $5,96 \mathrm{a}$ & $5,17 \mathrm{a}$ \\
\hline Efeito & $\mathrm{P} \leq 0,888$ & $P \leq 0,089$ & $\mathrm{P} \leq 0,723$ & $\mathrm{P} \leq 0,987$ & $\mathrm{P} \leq 0,460$ \\
\hline DMS & 0,75 & 0,63 & 1,25 & 1,41 & 1,14 \\
\hline
\end{tabular}

A temperatura de criação teve forte influência sobre o título de anticorpos para VDN (Tabela 6), pois, mesmo antes da vacinação, aves mantidas em ambiente frio apresentaram menor $(7,03 ; \mathrm{P} \leq 0,033)$ título referente à imunidade materna para VDN em relação às aves mantidas em ambiente termoneutro $(7,69)$, enquanto as aves mantidas em ambiente quente não diferiram daquelas mantidas nas demais temperaturas de criação $(7,41 ; \mathrm{P}>0,05)$. Esse fato mostra que já nos primeiros dias de vida as aves são mais sensíveis às baixas temperaturas. O estresse agudo causado pela temperatura fria pode ter elevado os níveis de corticosterona, que, segundo Gross (1988), tem a capacidade de reduzir a produção de anticorpos.

Nas análises imunológicas realizadas no 170 dia, ocorreu efeito mais acentuado, de modo que as aves mantidas em temperatura termoneutra apresentaram menor título $(5,62 ; \mathrm{P}<0,001)$, enquanto aquelas mantidas em ambiente quente, o melhor $(7,44 ; \mathrm{P}<0,001)$ e as mantidas em ambiente frio, título intermediário $(6,44 ; \mathrm{P}<0,001)$. Estes resultados comprovam que a temperatura quente ou fria promoveu efeito benéfico sobre a resposta imune. Resultados semelhantes foram observados por Ahmad et al. (2006), que, ao submeterem frangos a alimentação contínua, alimentação intermitente (1 hora alimento e 3 horas sem alimento) e retirada de alimentação das 9 as 17 $\mathrm{h}$, com o intuito de se promover estresse nas aves, observaram que o peso vivo dos animais foi menor apenas no grupo com alimentação intermitente, porém a produção de anticorpos para VDN foi maior para alimentação intermitente e o pior para as aves com alimentação contínua. Ribeiro et al. (2008) também observaram que aves aos 35 dias de idade submetidas ao estresse pelo calor apresentaram maior produção de anticorpos antiBSA (albumina sérica bovina). Assim, acredita-se que um leve estresse nas aves pode melhorar a resposta imune.

No $27^{\circ}$ e $37^{\circ}$ dia as aves apresentaram altos títulos de anticorpos para VDN, porém não foram observadas diferenças significativas entre as diferentes temperaturas. Aos 47 dias, as aves mantidas em ambiente frio apresentaram declínio significativo no título de anticorpos em relação às outras temperaturas de criação. Todavia, nesta idade, os resultados sorológicos não são tão importantes como nas outras idades avaliadas, visto que, normalmente nesta idade as aves estão sendo ou já foram abatidas.

\section{Conclusões}

A suplementação da ração de frangos de corte com cromo complexado à levedura ao nível de $400 \mu \mathrm{g} / \mathrm{kg}$ de ração melhora a viabilidade criatória e em ambientes quentes a conversão alimentar.

\section{Agradecimentos}

À Profa. Hirasilva Borba Alves de Souza, Técnica Tânia Mara Azevedo Lima e pós-graduandos Gabriel Maurício Peruca de Melo, Elisabete Regina Leone Pelicano, Fabio Roberto Leonel e Aniê Ieda Francabandiera, pela preciosa ajuda no desenvolvimento e análises experimentais. À Fapesp pelo auxílio financeiro para execução do projeto; $\mathrm{e}$ ao CNPQ, pela bolsa de estudo. 


\section{Referências}

AHMAD, F.; MAHMOOD, S.; REHMAN, Z.U. et al. Effect of feeding management on thermoregulation, production performance and immunological response of broilers during summer. International Journal of Agriculture \& Biology, v.8, p50-53, 2006.

AIN BAZIZ, H.A.; GERAERT, P.A.; PADILHA, JC.F. et al. Chronic heat exposure enhances fat deposition and modifies muscle and fat deposition in broiler carcass. Poultry Science, v.75, p.505-513, 1996.

ANANDHI, M.; MATHIVANAN, R.; VISWANATHAN, K. et al. Dietary inclusion of organic chromium on production and carcass characteristics of broilers. International Journal of Poultry Science, v.5, p.880-884, 2006.

BHASKARAM, P. Immunobiology of mild micronutrient deficiencies. British Journal of Nutrition, v.85, p.75-80, 2001.

CHEN, K.L.; LU, J.J.; LIEN, F.F. et al. Effects of chromium nicotinate on performance, carcase characteristics and blood chemistry of growing turkeys. British Poultry Science, v.42, p.399-404, 2001 .

CUNNIGHAM, C.H. Virologia practica. 6.ed. Zaragoza: Acribia, 1971. 260p.

DEBSKI, B.; ZALEWSKI, W.; GRALAK, M.A. et al. Chromiumyeast supplementation of chicken broilers in an industrial farming system. Journal of trace elements in Medicine an Biology, v.18, p.47-51, 2004.

GERAERT, P.A.; PADILHA, J.C.F.; GUILLAUMIN, S. Metabolic and endocrine changes induced by chronic heat exposure in broiler chickens: growth performance, body composition and energy retention. British Journal of Nutrition, v.75, p.195-204, 1996.

GROSS, W.B. Effect of ascorbic acid on antibody response of stressed and unstressed chickens. Avian Disiase, v.32, p.483-485, 1988.

GUO, Y.L.; LUO, X.G.; HAO, Z.L. et al. Effect of chromium on growth performance, serum biochemical traits, immune functions and carcass quality of broiler chickens. Scientia Agricultura Sinica, v.32, p.79-86, 1999.

HOSSAIN, S.M. Beneficios del cromo orgánico. Industria Avícola, v.45, p.14, 1998.

KHEIRI, F.; TOGHYANI, M. Effect of different levels of inorganic chromium on performance and immunity of broilers chicks. Journal of Animal and Veterinary Advances, v.8, p.1819-1823, 2009.

KRÓLICZEWSKA, B.; ZAWADZKI, W.; SKIBA, T. et al. Effects of chromium supplementation on chicken broiler growth and carcass characteristics. Acta Veterianaria Brunensis, v.74, p.543-549, 2005 .

LEE, D.N.; WU, F.Y.; CHENG, Y.H. et al. Effects of dietary chromium picolinate supplementation on growth performance and immune responses of broilers. Asian Australasian Journal of Animal Sciences, v.16, p.227-233, 2003

LIEN, T.F.; HORNG, Y.M.; YANG, K.H. Performance, serum characteristics, carcase traits and lipid metabolism of broiler as affected by supplement of chromim picolinate. British Poultry Science, v.40, p.357-363, 1999.

LITWACK, F.; SINGER, S. Subcellular actions of glucocorticoids. In: Biological actions of hormones. New York: Academic Press, 1972. p.114-165.

FURLAN, R.L.; MACARI, M. Termorregulação. In: MACARI, M.; FURLAN, R.L.; GONZALES, E. (Eds.) Fisiologia aviária aplicada a frangos de corte. 2.ed. Jaboticabal: FUNEP, 2002. p.209-230.

MASHALY, M.M.; TROUT, J.M.; HENDRICKS, G. et al. The role of neuroendocrine immune interactions in the initiation of humoral immunity in chickens. Domestic Animal Endocrinology, v. 15, p.409-422, 1998
MAY, J.D.; LOTT, B.D. The effect of environmental temperature on growth and feed conversion of broilers to 21 days of age. Poultry Science, v.79, p.669-671, 2000.

MENDES, A.A. Rendimento e qualidade da carcaça de frangos de corte. In: CONFERÊNCIA APINCO 2001 DE CIÊNCIA E TECNOLOGIA AVÍCOLAS, 2001, Campinas. Anais... Campinas: Facta, 2001. p.79-99.

NATIONAL RESEARCH COUNCIL - NRC. Nutrient requirements of domestic animals. Nutrient requirements of poultry. 9.ed. Washington, D.C.: National Academy Press, 1994. 155p.

NOLAN, W.F.; WEATHERS, W.W.; STURKIE, P.D. Thermally induced peripheral blood flow changes in chickens. Journal of Applied Physiology, v.44, p.81-84, 1978.

OLIVEIRA NETO, A.R.; OLIVEIRA, R.F.M.; DONZELE, J.L. et al. Efeito da temperatura ambiente sobre o desempenho e característica de carcaça de frangos de corte alimentados com dieta controlada e dois níveis de energia metabolizável. Revista Brasileira de Zootecnia, v.29, p.183-190, 2000.

PAULILO, A.C. Doença de Newcastle. IV. Ensaio experimental de diferentes vias de vacinação com a estirpe lentogênica LaSota em frangos de corte. Ars Veterinária, v.3, p.73-79, 1987.

PUVADOLPIROD, S.; THAXTON, J.P. Model of physiological stress in chickens 4. Digestion and metabolism. Poultry Science, v.79, p.383-390, 2000 .

RIBEIRO, A.M.L.; VOGT, L.K.; CANAL, C.W. et al. Suplementação de vitaminas e minerais orgânicos e sua ação sobre a imunocompetência de frangos de corte submetidos a estresse por calor. Revista Brasileira de Zootecnia, v.37, p.636-644, 2008

SAHIN, K.; SAHIN, N.; ONDERCI, M. et al. Optimal dietary concentration of chromium for alleviating the effect of heat stress on growth, carcass qualities, end some serum metabolites of broiler chickens. Biological Trace Element Research, v.89, p.53-64, 2002.

SANDS, J.S.; SMITH, M.O. Broilers in heat stress conditions: Effects of dietary manganese proteinate or chromium picolinate supplementation. The Journal of Applied poultry research, v. 8, p.280-287, 1999.

SOUZA, L.M.G.; MURAKAMI, A.E.; FERNANDES, J.I.M. et al. Influência do cromo no desempenho, na qualidade da carne e no teor de lipídeos no plasma sanguíneo de frangos de corte. Revista Brasileira de Zootecnia, v.39, p.808-814, 2010.

SUKSOMBAT, W.; KANCHANATAWEE, S. Effects of various sources and levels of chromium on performance of broilers Asian Australasian Journal of Animal Science, v. 18 , p.1628-1633, 2005

TemiM, S.; Chagneau, A.M.; GUillaummin, S. et al. Does excess dietary protein improved growth performance and carcass characteristics in heat exposed chickens? Poultry Science, v.79, p.312-317, 2000.

VAZ, R.G.; OLIVEIRA, M.V.; DONZELE, J.L. et al. Níveis de cromo orgânico em ração para frangos de corte mantidos sob estresse por calor no período de um a 42 dias de idade. Arquivo Brasileiro de Medicina Veterinária e Zootecnia, v.61, p.484-490, 2009.

WALKER, B. Chromium: the essential mineral. Health Foods Business, v.5, p.51-52, 1993.

WALLIS, I.R.; BALNAVE, D. The influence of environmental temperature, age, and sex on the digestibility of amino acids in growing broiler chickens. British Poultry Science, v.25, p.401-407, 1984.

WANG, J.Y.; TSUKAYAMA, D.T.; WICKLUND, B.H. et al. Inhibition of $\mathrm{T}$ and $\mathrm{B}$ cell proliferation by titanium, cobalt and chromium: Role of IL-2 and IL-6. Journal of Biomedical Materials Research, v.32, p.655, 661, 1996.

WANG, D.L.; ZHANG, M.H.; DU, R. et al. Effect of dietary chromium picolinate level on growth performance, immune function and carcass fat content of broilers. Acta Zoonutrimenta Sinica, v.11, p.19-23, 1999. 